\title{
Perawatan Saluran Akar Satu Kali Kunjungan Dengan Restorasi Mahkota PFM Pada Gigi Premolar Kedua Kiri Rahang Bawah: Laporan Kasus
}

\author{
Ika Putri Wiratama ${ }^{1}$, Yolanda ${ }^{2}$ \\ ${ }^{1}$ Mahasiswa PPDGS Konservasi Gigi, Fakultas Kedokteran Gigi \\ Universitas Padjadjaran \\ ${ }^{2}$ Staf Pengajar Departemen Konservasi Gigi, Fakultas Kedokteran Gigi \\ Universitas Padjadjaran \\ *korespondensi: ikaputriwiratama@gmail.com
}

\begin{abstract}
ABSTRAK
Pendahuluan: Perawatan saluran akar satu kali kunjungan merupakan perawatan yang terdiri dari instrumentasi kemo-mekanis hingga obturasi sistem saluran akar yang dilakukan dalam satu kunjungan. Restorasi full-coverage merupakan salah satu pilihan perawatan pada gigi pasca perawatan endodontik. Hal ini disebabkan oleh anatomi saluran akar yang kompleks, ruang interoklusal yang terbatas dan beban oklusal yang diterima oleh gigi tersebut. Laporan kasus: Pasien perempuan 28 tahun datang ke Klinik Konservasi Gigi RSGM UNPAD dengan keluhan gigi bagian bawah belakang kiri terasa sakit terutama ketika makan dan minum dingin sejak 1 minggu sebelumnya. Pemeriksaan klinis menunjukkan karies profunda pada gigi 35. Tes sensibilitas pada gigi 35 menunjukkan respon positif, dan respon negatif pada tes perkusi dan palpasi. Pemeriksaan radiografi menunjukkan area periapikal normal. Diagnosis gigi 35 adalah pulpitis irreversible asimptomatik dengan rencana perawatan saluran akar satu kali kunjungan dan restorasi full-coverage sebagai restorasi pasca perawatan endodontik. Perawatan dimulai dengan informed consent dilanjutkan dengan prosedur anastesi, preparasi akses kemudian preparasi saluran akar menggunakan instrumen ProTaper Next. Pengisian saluran akar dilakukan pada kunjungan yang sama menggunakan gutta-percha dan sealer AH plus. Gigi 35 kemudian direstorasi dengan restorasi full-coverage berupa mahkota PFM (porcelain fused to metal) dan pasak fiber. Simpulan: Kesuksesan perawatan saluran akar bergantung dari kemampuan operator, aksesibilitas yang baik dan kooperatif pasien. Restorasi full-coverage dapat mencegah fraktur, reinfeksi saluran akar, dan menggantikan struktur gigi yang hilang. Laporan kasus ini menunjukkan keberhasilan perawatan saluran akar satu kali kunjungan dengan restorasi akhir mahkota PFM.
\end{abstract}

Kata Kunci : Perawatan saluran akar satu kali kunjungan, pulpitis irreversible asimptomatik, full-coverage restoration, restorasi mahkota $\mathrm{pfm}$ 


\title{
Single-Visit Endodontic Treatment With PFM Crown Restoration On Mandibular Second Premolar : Case Report
}

\begin{abstract}
Introduction: Single-visit endodontic therapy is a treatment consisting of chemo-mechanical instrumentation to the obturation of the root canal system that is performed in a single-visit. Full-coverage restoration is one of the treatment options for tooth after endodontic treatment. This is due to the complex anatomy of the root canal, the limited interocclusal space, and the occlusal load received by the tooth. Case report: A 28 year old female patient came to the Conservative Dentistry Clinic, Dental Hospital UNPAD with a complaint of continuous pain when eating and drinking cold water of left lower posterior tooth since one week ago. Clinical examination showed deep caries in tooth 35. Sensibility testing of tooth 35 was responsive and non-responsive to percussion and palpation test. The radiograph examination revealed a normal periapical area. The diagnosis of tooth 35 was asymptomatic irreversible pulpitis with a treatment plan was single-visit endodontics and followed by by full-coverage restoration. The treatments began with informed consent followed by anesthetic procedures, access preparation then canal preparation using ProTaper Next instrument. Obturation was performed on the same visit using gutta-percha and AH plus sealer. The tooth was restored with full-coverage restoration using PFM (Porcelain fused to metal) crown with fiber post. Conclusion: The success of single-visit endodontic therapy depends on operator skills, good accessibility, and patients' cooperative. Full-coverage restoration can prevent fracture, reinfection of root canals, and replace lost tooth structure. This case report shows the successful treatment of single-visit endodontic with final PFM crown restoration.
\end{abstract}

Key Words : Single-visit endodontic, asymptomatic irreversible pulpitis, full-coverage restoration, PFM crown restoration, 


\section{PENDAHULUAN}

Berdasarkan triad endodontik, perawatan saluran akar terdiri dari pengangkatan jaringan pulpa gigi yang terinfeksi, preparasi saluran akar dengan cairan irigasi yang tepat, dan kemudian mengisi saluran akar dengan menggunakan bahan pengisi saluran akar. ${ }^{6}$ Perawatan saluran akar dapat dilakukan dengan perawatan multiple visit dan single visit. Multiple visit endodontic adalah norma yang ditetapkan di bidang endodontik dan dilakukan dalam beberapa kunjungan untuk pembersihan saluran akar secara menyeluruh. Single visit endodontic merupakan perawatan konservatif non-bedah pada gigi yang mengalami peradangan pulpa irreversibel yang terdiri dari preparasi kemomekanis lengkap dan obturasi sistem saluran akar dalam satu kunjungan. ${ }^{1}$

Indikasi dari single visit endodontic adalah pada kasus pasien yang membutuhkan rehabilitasi mulut lengkap, pasien dengan gangguan fisik yang sulit datang berulang, pasien yang membutuhkan sedasi, pulpitis ireversibel simtomatis baik karena karies atau trauma tanpa komplikasi. Fraktur gigi anterior yang mengutamakan estetik, perawatan endodontik intensional, gigi non vital dengan sinus tract, serta pada kasus retreatment (selektif) juga merupakan salah satu indikasi dari single visit endodontic. Kontra indikasi untuk single visit endodontic adalah gigi dengan kelainan anatomis yang berat, pasien yang mempunyai riwayat alergi, pasien dengan kelainan TMJ, gigi dengan akses terbatas, dan pada banyak kasus retreatment. ${ }^{3}$ Dengan perkembangan alat dan bahan kedokteran gigi modern pada saat ini, seperti penggunaan rubber dam, apex locator, sistem jarum rotary, sistem disinfeksi ultrasonik dan teknik obturasi terbaru dapat menunjang perawatan single visit endodontic sehingga perawatan dapat dilakukan lebih cepat, diterima dengan baik oleh pasien dan juga mencegah rekontaminasi saluran akar. ${ }^{1}$

Gigi yang telah dirawat endodontik mempunyai sifat mekanis yang berbeda secara signifikan dibandingkan dengan gigi vital. Perubahan pada sifat biomekanik dan integritas struktural gigi kemungkinan besar disebabkan oleh hilangnya volume jaringan keras, luasnya lesi karies, fraktur yang luas dan preparasi kavitas akhir sebelum terapi endodontik. ${ }^{14}$ Menurut Goerig et al, pada gigi premolar ditemukan bahwa gaya ekskursif lateral dapat menggeser cusp yang tersisa atau dapat menyebabkan fraktur akar vertikal, sehingga diperlukan restorasi dengan full coverage untuk mencegah hal tersebut terjadi. ${ }^{2}$ Pasak dapat meningkatkan ketahanan fraktur pada gigi yang dirawat secara endodontik. Dengan demikian, gigi premolar membutuhkan penempatan pasak dan mahkota untuk dapat mendistribusikan gaya secara homogen. Restorasi pada gigi pasca perawatan endodontik sangat penting untuk keberhasilan perawatan. Restorasi akhir yang ideal harus dapat melindungi permukaan oklusal dan menggantikan bonjol yang hilang agar dapat secara optimal melindungi struktur mahkota gigi, memiliki retensi agar restorasi tidak lepas dan memiliki resistensi agar mampu menahan daya kunyah. Selain itu, restorasi akhir juga harus mampu mengembalikan fungsi gigi, yaitu fungsi pengunyahan, estetik, bicara, dan menjaga gigi antagonis dan gigi sebelahnya. ${ }^{7}$

Mahkota porselen fused to metal (pfm) digunakan untuk memulihkan gigi yang rusak, melindungi sisa struktur gigi serta dapat mempertahankan oklusi dan memberikan estetika. Mahkota ini dapat dijadikan suatu alternatif restorasi pasca endodontik. Mahkota PFM yang melekat pada core diperkuat dengan pasak fiber akan mencegah resiko gigi menjadi fraktur. ${ }^{5}$

Laporan kasus ini akan membahas mengenai manajemen perawatan saluran akar satu kali kunjungan pada gigi 35 dengan diagnosis pulpitis irreversible asimptomatik dan restorasi akhir menggunakan pasak fiber dengan mahkota pfm. Tujuan dari penulisan laporan kasus ini adalah untuk mengevaluasi keberhasilan perawatan saluran akar satu kali kunjungan dengan restorasi akhir pasak fiber dan mahkota porcelain fused to metal dalam mengembalikan fungsi gigi baik dari segi mastikasi maupun estetika. 


\section{LAPORAN KASUS}

Pasien perempuan 28 tahun datang ke Klinik PPDGS Konservasi Gigi RSGM FKG Unpad dengan keluhan gigi bagian bawah belakang kiri berlubang dan terasa sakit terutama jika masuk makan dan minuman dingin sejak 1 minggu sebelumnya. Gigi tersebut pernah terasa sakit spontan tapi hilang dengan sendirinya. Pasien merasa kurang nyaman saat gigi tersebut digunakan. Pasien sudah memeriksakan giginya ke klinik swasta 4 hari sebelumnya dan diberikan obat serta tambalan sementara. Pasien menginginkan giginya untuk segera dilakukan perawatan. Riwayat penyakit sistemik disangkal.

Hasil pemeriksaan fisik dan tanda vital menunjukkan tekanan darah 110/80 $\mathrm{mmHg}$, pernafasan 26x/menit dan nadi 88x/menit. Pada pemeriksaan ekstra oral menunjukkan wajah simetris, otot bibir normal, bibir tidak ada kelainan, TMJ normal, kelenjar limfe tidak teraba dan tidak sakit.

Pemeriksaan intra oral gigi 35 terdapat karies pada bagian distooklusal yang mencapai pulpa. Keadaan kebersihan rongga mulut pasien baik. Status lokalis terlihat gigi 35 menunjukkan tes vitalitas positif, perkusi, palpasi dan kegoyangan negative serta jaringan dalam batas normal (Gambar 1).

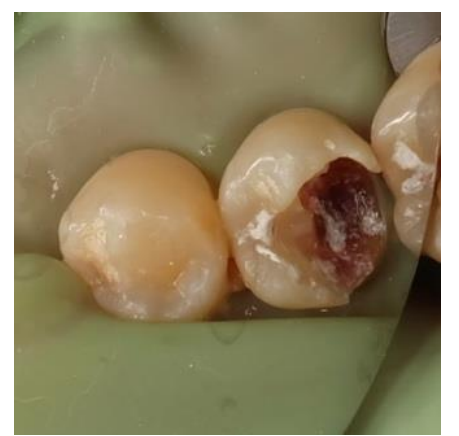

\section{Gambar 1. Gambaran klinis pada kunjungan pertama}

Pemeriksaan radiologis gigi 35 pada mahkota terdapat gambaran radiopak dari oklusal sampai kamar pulpa. Akar berjumlah satu dengan dua saluran akar. Membran periodontal, lamina dura dan periapikal dalam batas normal (Gambar 2).

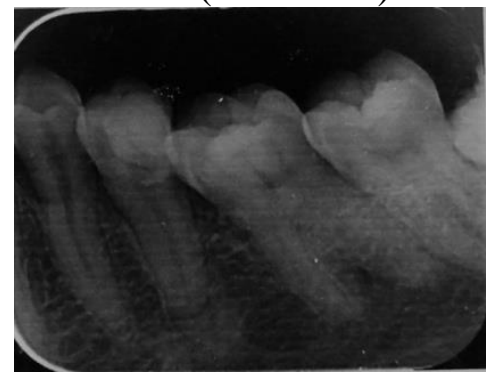

Gambar 2. Gambaran radiografik gigi 35 sebelum dilakukan perawatan.

Diagnosis pada gigi 35 adalah Pulpitis ireversibel asimptomatik (AAE, 2013). Rencana perawatan yang akan dilakukan pada gigi 35 meliputi perawatan saluran akar satu kali kunjungan dengan follow-up pemasangan pasak fiber dan mahkota porcelain fused to metal. Prognosis pada gigi ini adalah baik, karena pasien kooperatif serta memiliki motivasi untuk mengembalikan fungsi gigi, saluran akar lurus, tidak ada kelainan periapikal kondisi pasien tidak terdapat kelainan sistemik.

\section{TATA LAKSANA KASUS}

Pada kunjungan pertama dilakukan pemeriksaan subjektif, objektif, radiografi, penentuan diagnosis, rencana perawatan serta pasien diberi penjelasan secara lisan mengenai rencana perawatan dan tindakan apa yang akan dilakukan pada giginya. Selanjutnya dilakukan 
prosedur informed consent, dan pemeriksaan pra-anestesi. Pemeriksaan pra-anestesi didapatkan keadaan umum pasien baik, tidak ada penyakit sistemik, tekanan darah 110/80 $\mathrm{mmHg}$. Dilakukan tindakan asepsis pada daerah yang akan dianestesi dengan mengulaskan cairan povidon iodine $10 \%$ dibukal dan lingual gigi 35. Dilakukan anestesi infiltrasi pada bukal dan lingual gigi 35 menggunakan citoject dengan anestetikum Lidocaine $\mathrm{HCl}$ dan Epinephrine - Untuk memastikan keadaan teranestesi, dilakukan penekanan mukosa bukal dengan menggunakan ujung kaca mulut pada gigi 35 dan tidak terasa sakit.

Gigi 35 diisolasi dengan rubberdam, kemudian dilakukan ekskavasi karies dengan ekskavator dan selanjutnya dibuat cavity entrance dengan menggunakan bur diamond bundar steril. Kamar pulpa diakses dengan menggunakan bur akses endo dan ditemukan 2 orifis yaitu di bukal dan lingual (Gambar 3). Tahap selanjutnya adalah pembuatan pre endodontic buildup dengan menggunakan komposit.

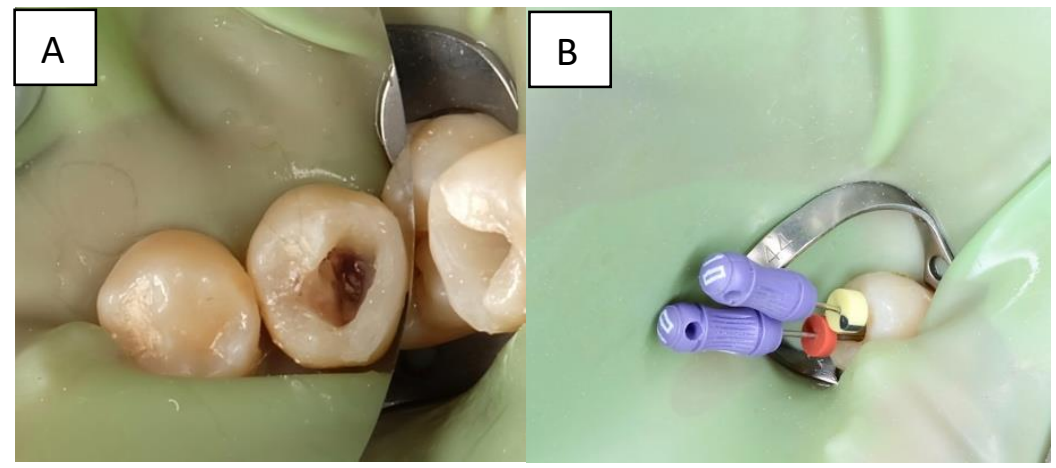

\section{Gambar 3. A. Pre Endododontic Build Up; B. Negosiasi saluran akar dengan file no. 10}

Setelah kamar pulpa terbuka, gigi diirigasi menggunakan larutan EDTA 17\% diikuti $\mathrm{NaOCl} 5,25 \%$ kemudian dilakukan ekstirpasi pulpa dengan menggunakan jarum barbed broach. Saluran akar dikeringkan dengan paper point. Negosiasi saluran akar menggunakan $k$ file \#10 dan pengukuran panjang kerja menggunakan apex locator diperoleh panjang kerja gigi 35 yaitu $21 \mathrm{~mm}$ bagian bukal dan $24 \mathrm{~mm}$ bagian lingual. Irigasi saluran akar dimulai dengan EDTA 17\% diikuti dengan akuades dan diakhiri dengan NaOCL 5,25\% serta melakukan agitasi menggunkan tip eddy sebagai aktivator irigasi setiap kenaikan nomor file. Preparasi dilanjutkan dengan menggunakan instrumen rotari Protaper Next (Dentsply) hingga X2. (Gambar 4).

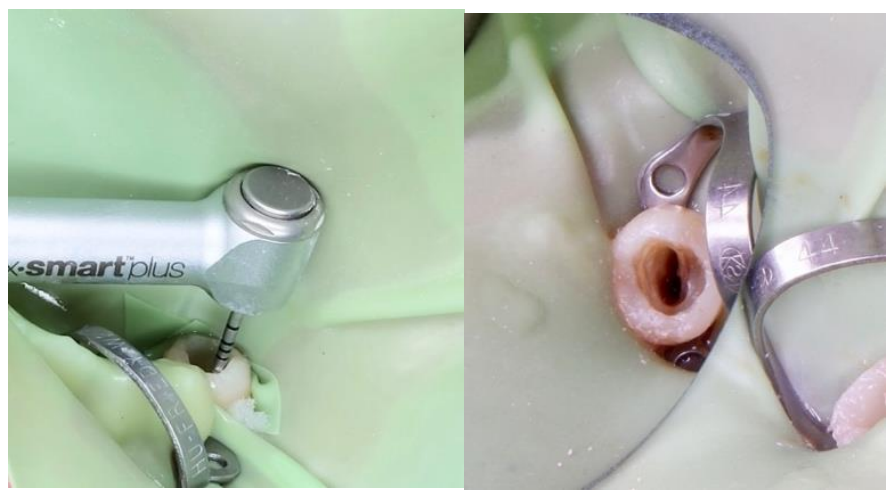

Gambar 4. File akhir yang digunakan adalah X2 
Saluran akar diirigasi kembali dengan $\mathrm{NaOCl} 5,25 \%$ diikuti dengan akuades dengan agitasi lalu dikeringkan dengan paper point streril. Foto periapikal untuk trial pengisian dilakukan dengan menggunakan master cone gutta percha \#25.06 (Gambar 5). Pengisian saluran akar dengan metode kondensasi lateral dilakukan dengan menggunakan resin based sealer AH Plus (Dentsply) dan gutta percha. Guttapercha dipotong $2 \mathrm{~mm}$ dibawah orifis dengan ekskavator yang dipanaskan. Hasil pengisian dikonfirmasi kembali dengan radiografi (Gambar 6). Selanjutnya dilakukan penutupan bagian koronal dengan gic kemudian ditutup dengan restorasi sementara. Pasien kontrol 1 minggu kemudian.

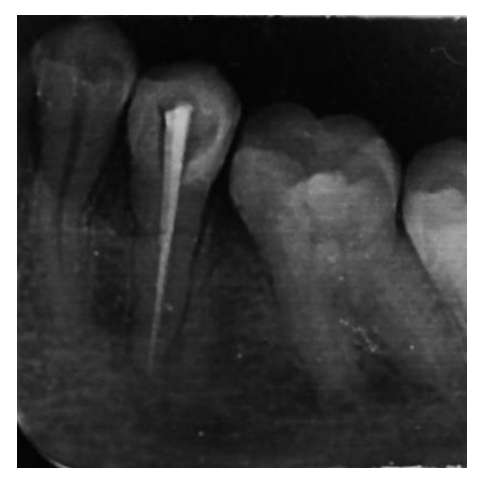

\section{Gambar 5. Foto ujicoba pengisian gutta percha}

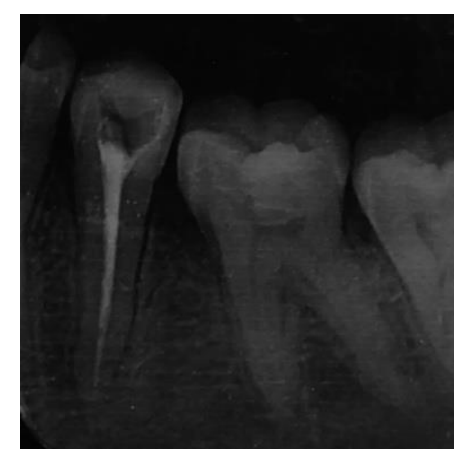

\section{Gambar 6. Gambaran radiologi hasil pengisian}

Pada kunjungan kedua dilakukan kontrol obturasi setelah 1 minggu perawatan saluran akar. Kontrol pasca obturasi memperlihatkan gigi 35 didapati asimptomatik, tidak ada respon pada tes perkusi dan tekan, serta tidak terdapat kegoyangan maupun kelainan pada jaringan periodontal disekitarnya. Pemeriksaan radiografik juga tidak menunjukkan abnormalitas (Gambar 7).

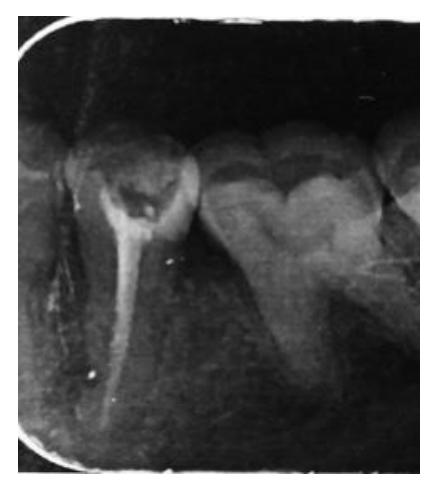

Gambar 7. Foto kontrol pengisian saluran akar 
Selanjutnya dilanjutkan dengan prosedur preparasi pasak dengan pembuangan guttapercha dan meninggalkan $5 \mathrm{~mm}$ di apikal menggunakan precission drill dengan kecepatan rendah lalu fiber post disiapkan dan dilakukan ujicoba ke dalam saluran akar (Gambar 8). Saluran akar diirigasi menggunakan $\mathrm{NaOCl} 5,25 \%$ lalu dibilas dengan akuades, selanjutnya dikeringkan dengan paper point. Dinding saluran akar selanjutnya dietsa 20 detik dibilas lalu aplikasi bonding disinar selama 20 detik kemudian dilanjutkan sementasi pasak fiber menggunakan semen self adhesive resin cement dual cures (Luxacore,DMG). Semen resin diinjeksikan ke dalam saluran akar, kemudian pasak yang telah diulasi semen dimasukkan ke dalam saluran akar dan selanjutnya dilakukan penyinaran selama 20 detik pada ujung pasak agar sinar dapat diteruskan melalui pasak fiber sehingga polimerisasi sempurna. Inti dari mahkota juga dibuat menggunakan semen resin self adhesive dual cure (Luxacore,DMG).

Pemilihan warna gigi menggunakan shade guide vitapan disesuaikan dengan warna gigi sebelahnya, ditetapkan dengan warna A3.5 (Vita Classical Shade Guide). Selanjutnya retraksi gingiva dilakukan dengan gingival retraction chord (\#00 Ultrapak, Ultradent). Preparasi inti restorasi dibuat dengan pengurangan di bagian oklusal menggunakan bur fisur minimal $1,5 \mathrm{~mm}$. Preparasi daerah bukal dan palatal dengan ketebalan $1.5 \mathrm{~mm}$ dengan akhiran berbentuk shoulder di bagian bukal dan champer di bagian palatal. Inti dibuat mengerucut ke oklusal membentuk sudut $6^{\circ}-8^{\circ}$. Seluruh sudut dibulatkan dan dihaluskan dengan menggunakan bor diamond fine grit (Gambar 8).

Pencatatan gigitan dilakukan pada pasien dengan menggunakan lilin merah. Pencetakan dilakukan dengan teknik double impression untuk mendapatkan model. Mahkota sementara dipasang selama pembuatan mahkota jaket metal porselen dan pasien diinstruksikan datang kembali satu minggu untuk dilakukan ujicoba (try in) mahkota PFM.

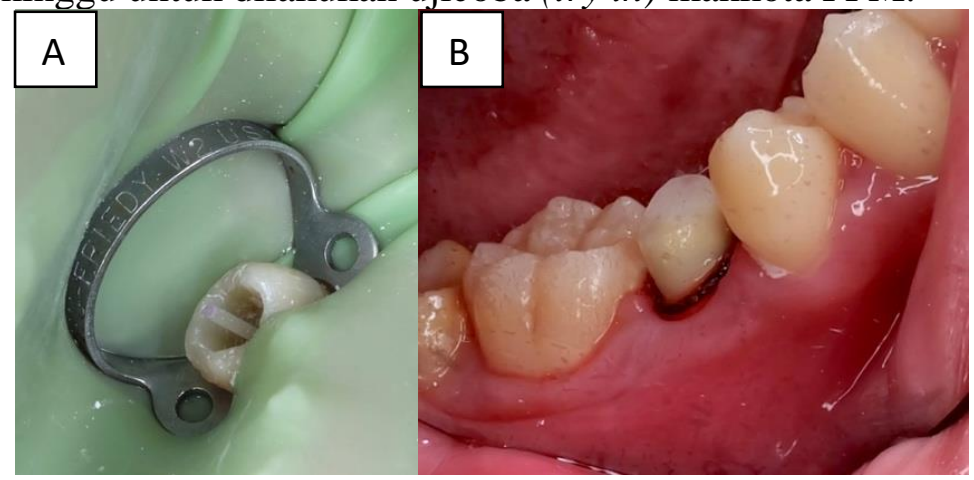

\section{Gambar 8. A. Insersi pasak; B. Preparasi mahkota PFM}

Pada kunjungan ketiga Gigi 35 kembali diperiksa secara klinis. Pemeriksaan memperlihatkan gigi 35 didapati asimptomatik, tidak ada respon pada tes perkusi dan tekan, serta tidak terdapat kegoyangan maupun kelainan pada jaringan periodontal disekitarnya. Pada kunjungan ini mahkota sementara dibuka dan kemudian dilakukan pengecekan core kembali. Try-in crown PFM memperlihatkan warna dengan gigi sebelahnya baik, adaptasi, kerapatan tepi, kontak proksimal, dan oklusi dalam keadaan baik. Gigi diisolasi menggunakan rubber dam kemudian dilakukan sementasi menggunakan lutting cement Fuji I. Kelebihan semen dibuang dengan menggunakan sonde dan dibersihkan dengan menggunakan cotton pellet. (Gambar 9). Kunjungan berikutnya dilakukan kontrol pemasangan crown PFM dan pemeriksaan radiografis dengan teknik bite wing. (Gambar 10). Pemeriksaan subjektif tidak terdapat keluhan penderita, dan pemeriksaan objektif perkusi dan palpasi negatif, tidak terdapat traumatik oklusi, dan crown masih terpasang dengan baik, serta pasien lebih nyaman saat ini. 


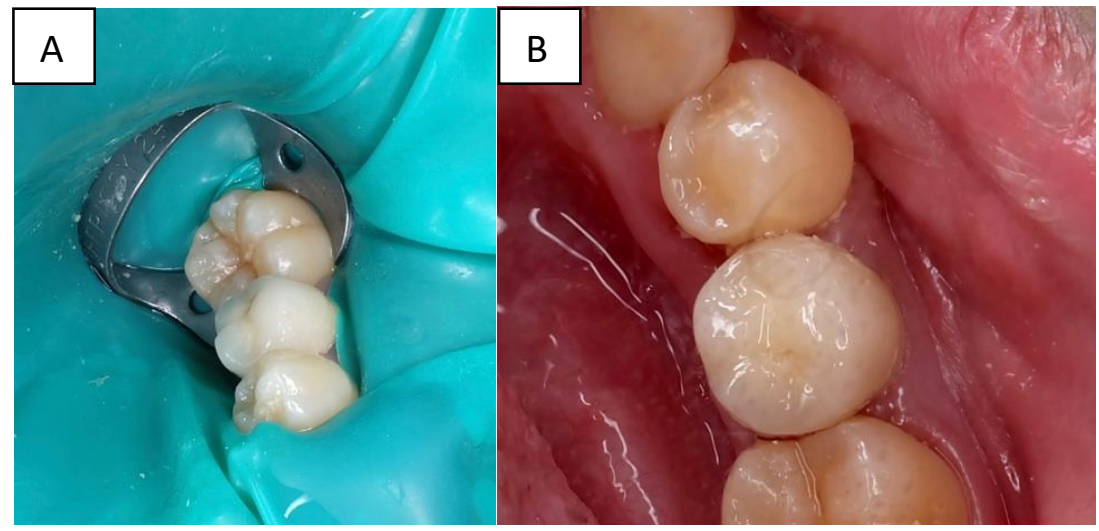

Gambar 9. A. Insersi mahkota PFM; B. Hasil akhir setelah sementasi

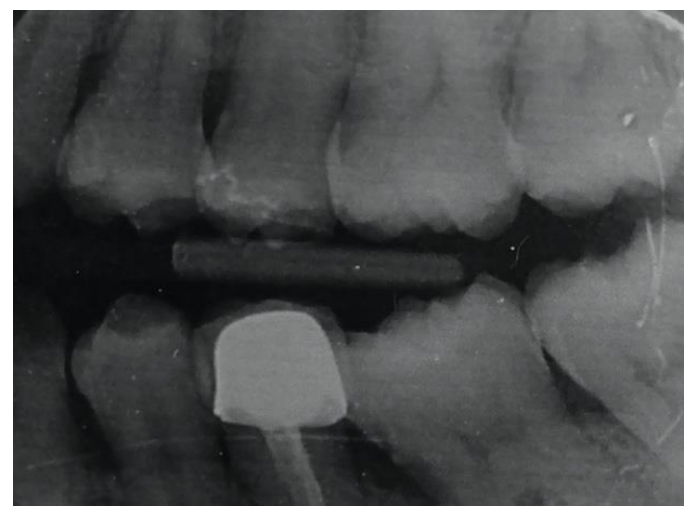

Gambar 10. Gambaran radiografis mahkota PFM pada gigi 35

\section{PEMBAHASAN}

Perawatan saluran akar merupakan suatu cara untuk mempertahankan gigi dalam rongga mulut. Tujuan perawatan saluran akar adalah untuk membersihkan kamar pulpa dan akar yang mengalami infeksi pulpa serta membentuk saluran akar agar dapat diobturasi secara hermetis sehingga seluruh sistem saluran akar tidak dapat berkomunikasi baik dengan jaringan periodontal maupun rongga mulut. ${ }^{3}$ Perawatan saluran akar satu kali kunjungan merupakan perawatan meliputi instrumentasi, desinfeksi dan obturasi sistem saluran akar dalam satu kunjungan. ${ }^{13}$ Konsep perawatan saluran akar satu kali kunjungan didasarkan pada "entombing theory" dimana sejumlah besar mikroorganisme dihilangkan selama pembersihan dan preparasi dan bakteri yang tersisa "dikubur" oleh obturasi saluran akar sehingga diharapkan bakteri akan kehilangan elemen penting untuk bertahan hidup yaitu nutrisi dan ruang. Selain itu, aktivitas antimikroba dari sealer atau ion zinc ( $\mathrm{Zn})$ dari gutta-percha dapat membunuh sisa bakteri. $^{3,9}$

Pertimbangan pemilihan perawatan saluran akar satu kali kunjungan pada kasus ini didasarkan oleh diagnosis pulpitis irreversible tanpa adanya kelainan periapikal, saluran akar lurus serta tidak ada kalsifikasi. Selain itu, pertimbangan lain adalah kendala waktu dari pasien sehingga pasien menginginkan agar secepatnya perawatan dapat diselesaikan.

Pada kasus ini, preparasi saluran akar dilakukan dengan teknik crown-down menggunakan file Protaper Next (Dentsply). Penggunaan teknik crown down pada kasus ini bertujuan untuk meminimalkan atau menghilangkan sejumlah jaringan nekrotik yang terekstrusi ke arah foramen apikal selama instrumentasi, selain itu preparasi yang diawali di daerah duapertiga koronal pada teknik ini akan meningkatkan penetrasi bahan irigasi dalam 
saluran akar. Jarum Protaper Next (Dentsply) mempunyai kelebihan seperti fleksibilitas, kekuatan dan ketahanan aus yang baik.

Selain itu, hal yang juga harus diperhatikan selama perawatan saluran akar adalah penggunaan rubber dam yang berfungsi sebagai isolasi kerja dan proteksi pasien saat menggunakan instrumen jarum endodontik serta bahan irigasi yang digunakan. ${ }^{11}$ Irigasi merupakan salah satu prosedur penting dalam perawatan endodontik, terutama pada perawatan saluran akar satu kali kunjungan. Selama dan setelah instrumentasi, bahan irigasi dapat memfasilitasi pembersihan mikroorganisme dan sisa jaringan dalam saluran akar. Dalam bidang endodontik, larutan irigasi yang paling umum digunakan adalah natrium hipoklorit ( $\mathrm{NaOCl} 5,25 \%$ ). Larutan ini memiliki kualitas dan sifat yang diinginkan yaitu efek antibakteri, dapat melarutkan bahan organik, dan sebagai lubrikan. EDTA $17 \%$ bertindak sebagai lubrikan yang mefasilitasi pergerakan instrumen pada saluran akar dan menghilangkan smear layer yang terbentuk selama preparasi saluran akar.

Pengisian saluran akar menggunakan sealer berbahan epoxy resin (AHPlus, Dentsply) dengan gutta-percha master cone menggunakan teknik kondensasi lateral. Sealer berbasis epoxy resin mempunyai sealing ability yang baik dengan dinding dentin saluran akar dan dapat mencegah kebocoran pada $1 / 3$ apikal. $^{9}$

Restorasi dari gigi yang telah dirawat endodontik bertujuan untuk melindungi struktur gigi yang tersisa dari fraktur dengan seminimal mungkin membuang jaringan gigi sehat, mencegah infeksi ulang pada sistem saluran akar, serta menggantikan struktur gigi yang hilang. ${ }^{4}$ Penelitian yang dilakukan oleh Aquilino dan Caplan menunjukkan bahwasanya pada gigi yang telah dirawat endodontik dan tidak dilakukan restorasi akhir dengan mahkota ditemukan 6x lebih rentan untuk hilang dibandingkan dengan gigi yang dilakukan restorasi akhir dengan mahkota. Selain itu, menurut Scotti et al, pada gigi yang telah dilakukan perawatan endodontik dengan sisa ketebalan dinding kurang dari $2 \mathrm{~mm}$, diperlukan cuspal coverage yang dapat digunakan dengan atau tanpa fiber post sehingga dapat memberikan ketahanan fraktur yang cukup baik. ${ }^{8}$

Gigi premolar mempunyai potensi lebih besar untuk terjadi fraktur yang berhubungan dalam gerakan lateral. Cusp gigi premolar mengalami serangkaian gaya yang kompleks yang dibentuk oleh axial loads dan shear loads. ${ }^{12}$ Pertimbangan mengenai jenis serta bahan restorasi ditentukan berdasarkan struktur gigi sehat yang tersisa. Masalah lain yang sering terjadi pada gigi yan telah dirawat endodontik adalah kebocoran mikro koronal dan kontaminasi bakteri yang terjadi jika tidak segera direstorasi, yang menyebabkan kegagalan endodontik dan memerlukan perawatan ulang. Maka dari itu, penggunaan restorasi bonded dapat dipertimbangkan untuk menghindari kebocoran mikro. ${ }^{7}$

Pertimbangan untuk mempertahankan gigi sebagai unit fungsional dalam jangka panjang harus memperhatikan jaringan gigi yang tersisa, posisi gigi, fungsi gigi, dan estetika. Selain itu kondisi jaringan periodontal harus masih baik agar dapat menentukan restorasi yang akan dibuat. ${ }^{15}$ Restorasi akhir yang digunakan pada kasus ini adalah mahkota porcelain fused to metal disertai pasak fiber. Pertimbangan pemilihan restorasi ini berdasarkan pada banyaknya struktur gigi yang rusak akibat karies dan tingginya risiko fraktur pada gigi. Restorasi porcelain fused to metal dipilih karena mempunyai ketahanan yang baik terhadap kekuatan fungsional terutama terhadap gaya lateral yang dihasilkan oleh gigi premolar selain itu mahkota ini memiliki kelebihan yaitu estetik yang baik, biokompatibel dan kerapatan marginal yang baik serta tidak mengalami penyusutan. ${ }^{5}$

Penggunaan pasak pada gigi yang telah dirawat endodontik harus memperhatikan struktur gigi yang tersisa dan kebutuhan fungsional. Struktur gigi radikuler yang minimal akan 
membutuhkan pasak fiber karena posisinya memiliki modulus elastisitas yang kira-kira sama dengan dentin dan gaya akan didistribusikan lebih merata di akar, sehingga kejadian fraktur akar lebih sedikit. Pasak yang digunakan pada kasus ini merupakan prefabricated glass fiber post. Pasak ini mempunyai biokompatibilitas yang baik, lebih estetis, serta memiliki modulus elastisitas yang menyerupai dentin. Sementasi pasak fiber menggunakan semen resin karena mempunyai beberapa keuntungan seperti estetik yang baik, kelarutan yang rendah, working dan setting time yang cukup dan meningkatkan kerapatan marginal. ${ }^{10,12}$

\section{SIMPULAN}

Perawatan satu kali kunjungan dengan restorasi pasak fiber dan mahkota porcelain fused to metal dapat dilakukan dengan baik dan dapat mengembalikan fungsi gigi termasuk mastikasi, estetik dan perlindungan terhadap jaringan pendukung gigi. Keunggulan dari perawatan ini adalah menyediakan rasa nyaman pada pasien dengan meminimalkan waktu kunjungan.

\section{DAFTAR PUSTAKA}

1. Ahmed F, Thosar N, Baliga MD, et al. Review Article Single Visit Endodontic Therapy: A Review. Austin J Dent. 2016;3(2): 10-35.

2. Al Dhalaan Reem. Prosthodontic management of endodontically treated teeth: Factors Determining post Selection, Foundation Restorations and Revies of Success \& Failure Data. Endoexperience Journal. 2008

3. Al-Rahabi M, Abdulkhayum AM. Single visit root canal treatment: Review. Saudi Endodontic Journal. 2012; Vol 2,Issue 2.

4. Carvalho MA, Lazari PC, Gresnigt Marco, et al. Current options concerning the endodontically treated teeth restoration with the adhesive approach. Braz. Oral Res. 2018;32:e74

5. Durr S., Muhammad Z. A. Porcelain Fused to Metal (PFM) Crowns and Caries in Adjacent Teeth. Journal of the College of Physicians and Surgeons Pakistan. 2011;21(3): 134-137

6. Estrela C, Bueno MR, Sousa Nets MD, Pecora JD. Method for determination of root curvature radius using cone-beam computed tomography images. Braz Dent J. 2008; 19:114-8

7. Faria Adriana C, Rodrigues Renata C, Antunes Rossana P. Endodontically treated teeth: Characteristics and considerations to restore them. Journal of Prosthodontic Research.2011;69-74

8. Liu Min Chieh. Restoration of Endodontically Treated Premolars and Molars: A Review of Rationales and Techniques. Journal of Prosthodontics and Implantology. Volume 3, Nuber 1, 2014.

9. Malhotra Neeraj, Shashirashmi Acharya. Contemporary endodontic approach: single visit root canal treatment revisited. A review. ENDO (Lond Eng) 2009;3(3):215-225

10. Papalexopoulos Dimokritos, Fillipatos Gerasimos. Restoring Endodontically Treated Teeth: From Immediate Restorations to the "Reverse" Preparation Approach. EC Dental Science 18.9 (2019): 2159-2168

11. Pecora Jesus D, Estrela Carlos, Estrela Cynthia. Common Operative Procedural Errors and Clinical Factors Associated with Root Canal Treatment. Brazilian Dental Journal. 2017;28(2):179-190 
12. Rocca Giovanni T, Krejci Ivo. Crown and post free adhesive restorations for endodontically treated posterior teeth from direct composite to endocrowns. Journal of the European Academy of Esthetic Dentistry. Volume 8. Number 2. Summer 2013

13. Schwendicke F, Gostemeyer G. Single visit or multiple visit root canal treatment: systematic review, meta analysis and trial sequential analysis. BMJ Open. 2017;7:e013115

14. Tikku Aseem, Bharti Ramesh, Chandra Anil. Are full cast crowns mandatory after endodontic treatment in posterior teeth. Journal of Conservative Dentistry. Oct-Des 2010. Vol 13. Issue 4

15. Weine FS. Endodontics Therapy. $6^{\text {th }}$ ed. Mosby, St. Louis, $2004: 546-584$ 